\title{
Hipertexto 2.0, folksonomia e memória coletiva: Um estudo das tags na organização da web ${ }^{1}$
}

\author{
Maria Clara Aquino \\ UFRGS \\ mcjobst@uol.com.br
}

\begin{abstract}
Resumo: A forma como os dados são representados, organizados $e$ recuperados na web é o centro da preocupação deste artigo. Partindo de um histórico do hipertexto, observando suas novas práticas e buscando demonstrar as possibilidades de criação de uma memória coletiva em determinados ambientes da web através da folksonomia, este trabalho se propõe a analisar estas novas formas de representação, organização $e$ recuperação de informações na web no intuito de elucidar uma nova fase do hipertexto, na qual o ideal de coletividade originário da prática pode então se concretizar.
\end{abstract}

Palavras-chave: hipertexto, folksonomia, tag.

Abstract: This article's main focus is an analysis of the way data is represented, organized and retrieved in the web. Starting from a hypertext's historic review, observing its new practices and trying to demonstrate the possibilities of creation of a collective memory in specific web environments through folksonomy, here, we suggest hypertext's new level, in which the initial ideal of collectivity can become concrete, and the formation of collective memory in social tagging systems is enhanced.

Keywords: hypertext, folksonomy, tag

${ }^{1}$ Trabalho apresentado à Revista E-Compós.

${ }_{2}^{2}$ Mestranda do Programa de Pós-Graduação em Comunicação e Informação da Universidade Federal do Rio Grande do Sul e bolsista do CNPq. 


\begin{abstract}
Abstrait: Le foyer principal de cet article est une analyse de la manière que des données sont représentées, organisé et recherché dans l'enchaînement. À partir de la revue historique d'un hypertexte, observant ses nouvelles pratiques et essayant de démontrer les possibilités de création d'une mémoire collective dans les environnements spécifiques d'enchaînement par folksonomy, ici, nous suggérons le nouveau niveau de l'hypertexte, dans lequel l'idéal initial de la collectivité peut devenir concret, et la formation de la mémoire collective dans les systèmes d'étiquetage sociaux est augmentée.
\end{abstract}

Most-clés: hypertexte, folksonomy, tag

Extracto : El foco principal de este artículo es un análisis de la manera que se representan, organizan e recuperand los datos en la web. Saliendo de la revisión histórica de un hipertexto, observando sus nuevas prácticas e intentando demostrar las posibilidades de creación de una memoria colectiva en ambientes específicos de la tela con folksonomia, aquí, sugerimos el nuevo nivel del hipertexto, en el cual el ideal inicial de la colectividad puede llegar a ser concreto, y la formación de la memoria colectiva en sistemas que marcan con etiqueta sociales se realza.

Palabras-clave: hipertexto, folksonomia, tag.

"The number of tags in a social network multiplies like rabbits" [Xu et al. 2006, online].

\title{
Introdução
}

Ao navegar na web é comum nos questionarmos como chegamos à determinada página. A navegação não-linear não surge com a Internet, nem com a web, já que o pensamento associativo é característico do ser humano, que num mero devaneio é capaz de se perder em meio à extensa rede de significações que percorre mentalmente. Ao ler um livro, assistir a um filme, escutar uma música, travar relações de comunicação, estamos constantemente formando um hipertexto mental, na medida em que pulamos de um assunto a outro estabelecendo relações entre os mesmos. Para Lévy (1993) qualquer fenômeno que envolva significações é um hipertexto ${ }^{3}$, já que a construção de sentido é sempre feita pelos atores da comunicação ou pelos elementos de uma mensagem; construção cuja estratégia associativa torna-se então explícita.

$3 \mathrm{O}$ hipertexto, neste trabalho, é encarado como uma forma de escrita coletiva e leitura nãolinear, mas também, da mesma forma que Lévy, é entendido como qualquer fenômeno que envolva significações. 
O hipertexto mental funciona, em partes, já que a nossa memória muitas vezes falha, mas ainda assim nossas lembranças são recuperadas através de uma rede de associações mentais que criamos em cada momento em que precisamos recuperar alguma informação. As lembranças, de acordo com autores como Halbwachs (2004); Sepúlveda (2003); Bartlett (SEPÚLVEDA, 2003); Casalegno (2006) entre outros, são possíveis não apenas com fragmentos de memória individual, ou seja, estes autores afirmam que a memória é sempre coletiva, na medida em que o homem é um ser social, que mantém experiências com outros homens e que assim sua memória é formada em conjunto com memórias alheias.

E na web? Na web também temos informações conectadas através dos links, mas, como estes dados são organizados? Quem os representa? Quem os organiza? E como os recuperamos? Essa montanha de informações constitui uma memória coletiva?

O hipertexto passou por três momentos (PRIMO E RECUERO, 2006). No primeiro encontramos processos hipertextuais praticados nos textos impressos; no segundo temos as páginas web, criadas por programadores, onde os usuários comuns da Internet podem, na maioria das vezes, não mais do que realizar uma navegação não-linear por entre as trilhas hipertextuais; e no terceiro, finalmente, o que seria a prática convergente com, mas também além daquela sonhada por autores como Ted Nelson e Vannevar Bush, a prática de um hipertexto construído de forma colaborativa, que se concretiza na web 2.0 cuja principal característica é a cooperação.

Dentro desse novo contexto da web emerge uma nova forma de representação, organização e recuperação de informações que funciona com base no hipertexto, subverte antigas formas de taxonomia ${ }^{4}$ e converge com os ideais de cooperação derivados da noção de web 2.0: a folksonomia que traduz o neologismo entre os termos folk e taxonomia, criado pelo arquiteto da informação Thomas Vander Wal (PRIMO, 2006, online). Trata-se de um sistema de indexação de informações que permite a adição de tags (etiquetas) que descrevem o conteúdo dos documentos armazenados. Baseada na livre organização, a folksonomia traz um novo

\footnotetext{
4 Forma de organização de informações através de classes, subclasses e vocabulário controlado.
} 
tipo de link, a tag, criada pelos próprios usuários da web, que assim, de forma coletiva representam, organizam e recuperam os dados na Rede.

A prática hipertextual significa relacionar assuntos, o que se faz através dos links. No momento em que são os próprios usuários, que ao utilizarem ferramentas cooperativas, organizam a informação de forma que possam recuperá-la através de uma busca por conexões e significados, em função da folksonomia, percebe-se a ocorrência de alteração dos padrões organizacionais dos dados na Rede.

Mas quais as implicações de um hipertexto construído coletivamente dentro deste novo momento da web? Qual o impacto dessas novas práticas na representação, organização e recuperação de informações? Quem são os responsáveis por esses novos formatos organizacionais? É possível uma organização colaborativa na construção da memória coletiva? Tantas pessoas gerando e gerenciando informação com tamanha liberdade não poderia causar um caos informacional?

Partindo de um histórico do hipertexto, observando suas novas práticas e buscando demonstrar as possibilidades de criação de uma memória coletiva em determinados ambientes da web através da folksonomia, este trabalho se propõe a analisar estas novas práticas de representação, organização e recuperação de informações na web no intuito de elucidar uma nova fase do hipertexto, na qual o ideal de coletividade originário da prática pode então se concretizar.

\section{Hipertexto: das marginalias à web 2.0}

Considerando a rede de associações entre significados que fazemos constantemente como um hipertexto mental, partimos para a observação do hipertexto em termos mais concretos. Ainda que o termo só tenha sido criado em 1965, já nos séculos XVI e XVII era possível visualizar a prática de uma escrita e de uma leitura hipertextuais, como nos lembra Burke (2003, p. 54) com os manuscritos da Europa Moderna e as alterações que sofriam nas transcrições; e Chartier (2002, p.14) quando resgata as marginalia, que seriam as anotações feitas nas margens das páginas dos livros antigos e que até hoje ainda são utilizadas.

As diferentes formas hipertextuais sempre trouxeram como característica a coletividade para sua construção. Nos manuscritos o texto era escrito coletivamente 
na medida em que era modificado com as transcrições; nas marginalias as anotações eram transferidas para "cadernos de lugares-comuns"5 para que pudessem ser posteriormente consultadas tornando estas anotações tão importantes quanto o texto inicial que as originou.

Já, em 1945, o hipertexto ganhou importância como forma de registro, organização e recuperação de informações, com o Memex de Bush, que além de conectar os dados, permitiria ${ }^{6}$ que comentários fossem adicionados aos arquivos armazenados. O mesmo ocorreu no projeto Xanadu7 de Ted Nelson, 20 anos depois, em 1965, ou seja, os documentos poderiam ser alterados, comentados e em ambos os sistemas as diferentes versões que um registro ia ganhando, ficariam armazenadas para posteriores consultas.

Em ambos os sistemas é possível perceber a intenção de construir um dispositivo que permitisse a representação, a organização e a recuperação das informações de forma conectada, além do intuito de armazenar esses dados, e no caso do Memex, intercambiar essas informações ${ }^{8}$; e no Projeto Xanadu, a ambição de congregar os documentos de forma a criar uma biblioteca universal, ambos como uma espécie de memória coletiva daquilo que seus usuários colocassem nos sistemas.

Em 1989, com a criação da web, por Tim Berners-Lee, esse potencial coletivo do hipertexto foi diminuído, tanto pelas limitações da linguagem HTML (HyperText Markup Language), quanto pelo fato de que nem todo internauta era livre para modificar as páginas que acessava, fosse em termos de conteúdo quando de linkagem, pois só o programador tinha esta liberdade. Porém, a Internet sempre se desenvolveu através da cooperação entre pesquisadores, acadêmicos, aficcionados, hackers, ou seja, foi evoluindo pelas mãos de seus usuários (MARTINS, 2006), ainda que tenha sido um projeto de iniciativa militar com objetivos de defesa e proteção de informações. Esta comunidade híbrida de usuários/colaboradores, hoje, parece mais

5 Os "cadernos de lugares-comuns" eram listas de marginalias e eram então publicados e disponibilizados para que outros leitores pudessem ler as anotações que leitores anteriores haviam feito aos textos.

${ }^{6}$ O Memex nunca chegou a ser construído.

7 O Projeto Xanadu nunca foi efetivado e até hoje é possível encontrar "More Later" na página de Ted Nelson.

8 Bush chamava de "trilhas associativas" os documentos conectados por cada usuário de um Memex. Esses usuários então, poderiam trocar entre si as trilhas que fossem criando. 
do que nunca, tentar fortalecer esse caráter cooperativo/coletivo; por isso hoje, tanto se ouve sobre web 2.09.

Encarando como a "segunda geração de serviços online", Primo (2006, online) caracteriza a web 2.0 como potencializadora das formas de publicação, compartilhamento e organização de informações. Para Tim O'Reilly, criador do termo, a web 2.0 não tem limites rígidos, mas sim um núcleo gravitacional, já que é encarada como uma plataforma, na qual os próprios usuários controlam seus dados, que não mais depende de pacotes fechados de software, mas de serviços que rodam no browser, online. A arquitetura é edificada sob a cooperação, como chama O`Reilly, uma "arquitetura de participação", na qual os dados possuem origem remixável e podem ser transformados, o que traduz a idéia do "beta eterno", onde tudo está sempre sendo construído de forma colaborativa, no intuito de atender às necessidades dos usuários. Com tudo isso, o que se busca é a formação de uma inteligência coletiva e, porque não dizer, uma memória coletiva.

Os novos formatos web 2.o permitem a visualização dos ideais de Bush e Ted Nelson, ou seja, o hipertexto é a forma utilizada para a representação, organização e recuperação das informações e é construído de forma coletiva, já que os usuários possuem a liberdade de interferir no conteúdo informacional.

Porém, nem todos concordam com tamanha liberdade. Como se questionou no início do texto, qual as conseqüências dessa liberdade? Não estaríamos beirando a uma babel informacional? É possível criar uma memória coletiva num ciberespaço onde a inserção e conexão de conteúdo torna-se tão flexível?

\section{Hipertexto 2.o, memória coletiva e folksonomia}

A principal crítica de Bush (1945, online) em As We May Think ${ }^{10}$ era aos sistemas de indexação de informações da época, por serem alfabéticos, ou numéricos, ou por classes e subclasses, ou seja, sempre dotados de alguma espécie de hierarquia que fazia com que diversas vezes o pesquisador fosse obrigado a reiniciar uma busca em função da falta de conexão entre os assuntos. Como o próprio título do ensaio de

\footnotetext{
9 Ver artigo de Tim O’Reilly sobre web 2.o. Disponível em:

http://www.oreillynet.com/pub/a/oreilly/tim/news/2005/o9/30/what-is-web-20.html

10 http://www.theatlantic.com/doc/194507/bush
} 
Bush diz (As We May Think - "Como podemos pensar"), ele acreditava que as informações deveriam ser armazenadas e depois consultadas através de um esquema similar ao pensamento humano, ou seja, de forma associativa.

A memória humana, que funciona de forma associativa, não realiza estas associações individualmente. De acordo com Halbwachs (2004, p. 42):

É difícil encontrar lembranças que nos levem a um momento em que nossas sensações fossem apenas o reflexo dos objetos exteriores, no qual não misturávamos nenhuma das imagens, nenhum dos pensamentos que nos prendiam aos homens e aos grupos que nos rodeavam. Se não recordamos de nossa primeira infância, é, com efeito, porque nossas impressões não se podem relacionar com esteio nenhum, enquanto não somos ainda um ente social.

A memória, nesse caso, é sempre coletiva, ou seja, construída com a ajuda de outras memórias, já que o homem é sempre um ente social. Halbwachs (2004, p. 41) até considera a existência de uma memória individual, a que ele vai chamar de "intuição sensível": um estado de consciência puramente individual, onde não entram elementos do pensamento social. São lembranças que reaparecem sem a necessidade de vinculá-las a nenhum grupo. A memória individual existe, mas nada mais é do que um ponto de vista sobre a memória coletiva, um ponto de vista mutante, que se altera em função do lugar que o indivíduo ocupa e em função do deslocamento desse lugar segundo as relações que o indivíduo mantêm com o meio social. A natureza da memória, é para Halbwachs (2004), uma natureza social.

Além de Halbwachs, Sepúlveda (2003) estudou o trabalho do psicólogo britânico Frederic Bartlett, que em 1932 estabeleceu uma série de conceitos para explicar os processos mentais decorrentes de interações sociais que seriam responsáveis pela lembrança e pelo esquecimento. Assim como Halbwachs, Sepúlveda (2003) afirma que Bartlett também considera a memória uma memória coletiva, resultado das interações entre indivíduos no presente. Ela acredita que a contribuição desses autores foi mostrar que a memória fazia parte de um processo social, de interação entre os indivíduos, a partir de estruturas sociais determinadas.

Mas porque dizer que é possível a potencialização de uma memória coletiva decorrente do processo de registro, organização e recuperação das informações na web 2.0? Devido à folksonomia. 


\subsection{Folksonomia: o vocabulário descontrolado}

Tradicionalmente os sistemas de representação, organização e recuperação de informações trabalharam através da taxonomia, organizando as informações através de classes e subclasses com um vocabulário controlado, que limita o pesquisador na medida em que o resultado das buscas é definido em função de uma determinada listagem de palavras relacionadas com determinado assunto. Se no momento da busca o pesquisador não utilizar alguma palavra da listagem criada para tal assunto, a busca não lhe trará resultados úteis. Além disso, esta listagem é feita por um profissional especializado em organizar informações e não pelo próprio corpo de profissionais de cada área e assim, muitas vezes, algum termo de extrema importância dentro de um campo pode ficar excluído da listagem de um vocabulário controlado (DREYFUS, 2001).

A web também possui seus problemas de representação, organização e recuperação de informações, ainda que as agregue de forma associativa. Por mais que haja esforços no âmbito da Inteligência Artificial, um computador ainda não é capaz de distinguir significados e assim, no momento de uma busca, pode apresentar resultados inúteis, quando, no caso de palavras que possuem mais de um significado em contextos diferentes, como por exemplo, nomes próprios e gírias.

A quantidade de informações na web e a forma como estão organizadas, ou desorganizadas, conectadas através de links que podem ligar um documento a qualquer outro sem nenhuma autoridade para a criação desses links, que então podem surgir de acordo com a intenção de quem quer que seja que os criou, são dificuldades na busca dos dados na web, segundo Dreyfus (2001). Para ele, os links não foram introduzidos porque são um modo mais fácil de encontrar informação, mas porque são uma forma natural de usar a velocidade e o poder de processamento dos computadores em relacionar uma grande quantidade de informações independente de significado e estrutura. Se tudo pode ser linkado com tudo desconsiderando o significado, o crescimento do tamanho da web e a arbitrariedade dos links dificultam a recuperação da informação. O autor também diz que o fracasso da I.A. é de que os computadores não entendem o senso comum, que influencia na organização das informações e que muda com o tempo, com o contexto. 
Num primeiro momento o posicionamento de Dreyfus (2001) tem sentido, frente ao que poderia parecer uma certa desorganização na web, porém, além de viabilizar a escrita coletiva online algumas das novas ferra mentas ${ }^{11}$, que surgem com o momento da web 2.o, agregam uma nova forma de representação, organização e recuperação de informações que vai de encontro aos postulados do autor. Estas ferramentas baseiam-se na folksonomia que é a possibilidade que o indivíduo tem de relacionar qualquer palavra à um dado que armazena nesses serviços. Esta relação é estabelecida através de uma tag $^{12}$ adicionada ao documento. Assim, a informação fica armazenada e pode ser recuperada através da tag que o próprio usuário criou, e não mais através de um vocabulário controlado, o qual muitas vezes é desconhecido de quem faz a busca.

Marlow et. al (2006, online) chamam de Tagging Social ${ }^{13}$ os sistemas que incorporam a folksonomia em seu funcionamento. Para os autores, a prática de "etiquetar" um recurso é semelhante à categorização de bookmarks ("favoritos"). Não é à toa que se fala em Bookmarking Social, que são ferramentas que consistem no armazenamento de bookmarks em serviços online, os tagging systems ${ }^{14}$. É possível então acessar de qualquer computador a lista de bookmarks, mas o diferencial está no fato de que o usuário de um serviço destes pode tornar pública a sua lista de bookmarks compartilhando-a com outros usuários (por isso "social” bookmarking) e associar tags (etiquetas) a determinados materiais.

O Tagging Social tem como exemplos mais fortes de sistemas de tagging o Flickr ${ }^{15}$ e o del.icio.us ${ }^{16}$. O Flickr é um sistema para armazenamento e compartilhamento de fotos, no qual os usuários podem armazenar e "etiquetar"17 fotos, manter uma rede de contatos com outros usuários do sistema e ainda adicionar tags em fotos alheias; e o del.icio.us possibilita o armazenamento e a associação de tags de páginas web e outros recursos.

\footnotetext{
${ }^{11}$ Como por exemplo, Flickr, del.icio.us e demais sistemas baseados na folksonomia.

12 O termo tag significa "etiqueta".

13 Do inglês: Social Tagging

14 Tradução da autora: sistema de tagging.

15 http://www.flickr.com

16 http://www.delicious.com

17 O verbo "etiquetar" será utilizado como tradução de “tagging”.
} 
Poderíamos dizer que a folksonomia é uma espécie de vocabulário descontrolado. Isso não quer dizer que o esquema seja uma desordem total, o que poderemos perceber ao longo desse texto. Na verdade, trata-se de um mecanismo de representação, organização e recuperação de informações que não é feito por especialistas anônimos, o que muitas vezes pode limitar a busca por não trazer determinadas palavras-chave, mas sim um modo onde os próprios indivíduos que buscam informação na rede ficam livres para representá-la, organizá-la e recuperá-la, realizando estas ações com base no senso comum e tendo assim um novo leque de opções ao efetuar uma pesquisa para encontrar algum dado.

Assim, este vocabulário descontrolado altera os padrões hipertextuais até então praticados, pois é construído de forma coletiva, permitindo uma organização semântica das informações, o que conseqüentemente amplia as possibilidades de busca dos dados na web.

\subsection{A memória coletiva através da folksonomia}

Levando em consideração que a memória faz parte de um processo social, de interação entre os indivíduos, a partir de estruturas sociais determinadas (SEPÚLVEDA, 2003), através dessa ferramentas que utilizam a folksonomia para conceder ao usuário a possibilidade de registrar, organizar e recuperar as informações através das tags que ele mesmo determinar e ainda compartilhar com outros indivíduos essas tags, percebe-se a construção de uma memória coletiva dentro da web, mais especificamente dentro de cada sistema folksonômico ${ }^{18}$. No momento em que as tags são criadas e publicadas está se compartilhando a memória daquilo que foi visitado na web com outros usuários, que estão fazendo a mesma coisa. Futuramente, o indivíduo não procura somente com suas tags, mas também com as dos outros, o que configura exatamente a forma como utilizamos nossa memória, recorrendo à experiências que tivemos com outros indivíduos.

...a teoria da memória de Halbwachs estabelece que indivíduos utilizam imagens do passado enquanto membros de grupos sociais, e usam convenções sociais que não são completamente criadas por eles. Indivíduos não recordam sozinhos, quer dizer, eles sempre

\footnotetext{
${ }_{18}$ Entende-se aqui como sistema folksonômico qualquer sistema que se utilize da folksonomia em seu funcionamento e permita a relação entre seus usuários que assim podem compartilhar tags.
} 
precisam da memória de outras pessoas para confirmar suas próprias recordações e para lhes dar resistência (SEPÚLVEDA 2003, p. 42,43).

Além da construção de uma memória coletiva nesses ambientes, o hipertexto também passa a ser coletivo, como era originalmente, na medida que os usuários do sistema podem gerenciar estas informações livremente, criando as tags, discutindo $^{19}$ sobre a melhor forma de utilizá-las, trocando-as entre si, buscando muitas vezes utilizar tags que correspondam ao senso comum para facilitar a busca de informações, não só para si, mas também para outros indivíduos.

Jöel de Rosnay (CASALEGNO, 2006) diz que, na sua concepção, existem vários tipos de memória, mas que em termos de relação entre memória, comunidade e redes, existe a memória implícita e a memória explícita. Por memória explícita, Rosnay entende as informações armazenadas em bases de dados, e que são encontradas com o auxílio de mecanismos de busca, e cita a Internet como um sistema que nos permite "esquecer as coisas e as reencontrar quando temos necessidade ou vontade" (CASALEGNO, 2006, p. 42). Já a memória implícita é para Rosnay, é aquela construída não via rede, mas uma memória que se autoconstrói e ele dá como exemplo o link.

Crio um link entre duas páginas da rede, e ao fazê-lo, crio um link implícito de memória, um link que cria um contato entre dois neurônios, uma via de acesso. Na Internet, são todos esses caminhos de memorização que são extremamente interessantes, são esses links que se constituem, independentemente das pessoas. Trata-se de uma memória referencial, implícita, ecossistêmica de certo tipo (revela do que se poderia chamar de um ecossistema informacional) - e isso eu acho apaixonante (CASALEGNO, 2006, p. 42).

A proliferação de links, através dos sites, que assim tecem redes, conexões entre si, é o que para Rosnay (CASALEGNO, 2006) forma a memória da rede. Rosnay (CASALEGNO, 2006) diz que a velocidade de troca e de busca de informações na Internet é o que favorece a memória coletiva, para ele, uma memória dinâmica, construída pelas pessoas, que devem ter a oportunidade não só de se conectarem, mas de intercriarem e interagirem.

19 O del.icio.us mantém um blog (http://blog.del.icio.us/) onde publica as novidades incorporadas ao sistema, discute folksonomia, a forma como o sistema vem sendo desenvolvido e conta com os comentários dos usuários que assim podem opinar sobre o andamento da ferramenta. 
Ainda que considerando a conexão das informações na web não no sentido da folksonomia, é possível comparar o pensamento de Rosnay com os sistemas folksonômicos onde os usuários, intercriando e interagindo organizam as informações através das tags e conseqüentemente criam uma memória coletiva que auxilia na busca dos dados na Rede.

Esse esforço coletivo praticado com a folksonomia rebate a idéia que Dreyfus tem dos links quanto à q uestão semântica. Para ele, "since hyperlinks are made for all sorts of reasons and since there is only one basic type of link, the searcher cannot use the meaning of the links to arrive at the information he is seeking” ${ }^{20}$. A folksonomia, nesse momento, através desse vocabulário descontrolado cria um novo tipo de hipertexto, o hipertexto $2.0^{21}$ que encarna um novo tipo de link, a tag. O registro, organização e recuperação de informações através da folksonomia é então feito através desse hipertexto que é praticado de forma coletiva, conectando as informações através das tags. Ao contrário de Dreyfus (2001), não existe somente um tipo de link, e isso é possível perceber através da classificação proposta por Landow (2006), que elenca nove tipos de links ${ }^{22}$, pelo Co-link (www.co-link.org), sistema que permite a criação de links multidirecionais, mas principalmente pelas tags, que são um tipo de link baseado no significado, no conteúdo do documento "etiquetado". O armazenamento dessas tags forma então uma memória coletiva dos usuários que as criaram e que assim, podem, posteriormente, recorrer às próprias ou alheias tags para recuperar informações.

\section{Obstáculos da folksonomia}

Porém a folksonomia, assim como a taxonomia, apresenta seus problemas. Em uma crítica à forma como as informações são dispostas na web, Dreyfus (2001, p. 10) acredita que "without the demands of a practice to constrain what should be

${ }^{20}$ Tradução da autora: Como os links são feitos por diversos motivos e como existe apenas um tipo básico de link, o pesquisador não pode usar o significado dos links para chegar até a informação que ele está procurando.

${ }^{21}$ Ainda que se tenha dito no início do artigo, de acordo com Primo e Recuero (2006) que o hipertexto vive um terceiro momento, após ter sido praticado no impresso, depois no digital e agora no contexto web 2.0, o termo hipertexto 2.0 aqui mencionado, assim o foi para convergir com o termo web 2.0.

${ }_{22}$ Landow propõe uma classificação onde elenca 11 tipos de links baseando-se em como podem ser percorridos. Ver LANDOW, George. Hypertext 3.o: Critical theory and new media in an era of globazation. 2006. 
linked to what, the links can proliferate wildly. [...] There are no hierarchies; everything is linked to everythin else on a single level"23.

O postulado do autor, se aplicado à folksonomia, não é passível de se deixar de lado, pois como questionou-se ao início do texto, a liberdade de criação das tags não poderia causar um crescimento absurdo do número de informações na web? Prefere-se acreditar que as informações não estariam aumentando em função das tags, mas mais, ou melhor, do que isso, estariam sendo mais bem organizadas.

Ainda que para Dreyfus (2001) possa parecer que na web a quantidade de conexões importe mais do que a qualidades dessas conexões, é possível perceber que a folksonomia não tem sido praticada de forma dispersa e descontrolada na web, o que poderia causar a desorientação no momento da busca. Dois exemplos: O usuário do del.icio.us ao adicionar uma tag à determinada página, no momento de escolha do termo a utilizar como tag recebe do sistema uma lista das tags mais utilizadas daquela página.Ele pode ou não utilizá-las, até mesmo mais de uma, ainda que fique livre para criar outra. Quando não existe nenhuma tag relacionada, aí então ele pode criar uma nova tag. Obviamente, para facilitar a busca o usuário acaba utilizando as tags já criadas, o que conseqüentemente contribui para os outros usuários. No Flickr, é comum a formação de redes de usuários (como comunidades) em torno dos álbuns de fotos, o que permite que cada usuário compartilhe suas tags com os usuários que são seus "conhecidos", adicione tags às fotos alheias e também realize buscas no sistema através de tags comuns.

A questão social que os sistemas suscitam refere-se não só ao fato de as pessoas estarem utilizando estas tags de forma colaborativa, já que as adicionam tanto nos seus dados como nos dados dos outros, mas também à motivação pela qual as pessoas estão utilizando este tipo de serviço. Marlow et. al (2006, online) dizem que os usuários são motivados tanto pelas necessidades pessoais como pelos interesses sociais, mas que o que determina a utilização das tags varia entre as pessoas e os sistemas. Os autores acreditam que nem todas as tags emergem com o intuito de terem audiência, ou seja, que a pessoa nem sempre adiciona uma tag e a

\footnotetext{
23 Tradução da autora: sem a busca por uma prática que limite o que deva ser linkado com o que, os links podem proliferar descontroladamente. [...] Não há hierarquias; tudo é linkado com tudo no mesmo nível.
} 
torna pública; muitas vezes o que se quer é organizar os próprios dados. Para eles, muitos começam com a idéia de que estão adicionando tags para seu próprio benefício em termos de organização; outros acabam percebendo e apreciando os aspectos sociais da prática; enquanto outros permanecem sem o mínimo interesse em compartilhar suas tags com outras pessoas. Por isso eles classificam a motivação em organizacional (no sentido de disposição das informações) e social, e que aqui nos importam, respectivamente, pelo fato de analisarmos o hipertexto 2.0 como ferramenta da folksonomia para registro, organização e recuperação das informações e como responsável, através de sua prática coletiva, pela formação de memória coletiva dentro desses ambientes.

Nesta linha de raciocínio, Walker vai descrever o processo de tagging como um 'feral hypertext', a structure out of control, where the same tag is assigned to different resources with different semantic senses, and thus associates otherwise unrelated resources"24 (WALKER, apud MARLOW et. al, 2006 ONLINE). Ao adicionar tags a uma informação na web estamos ativando uma rede de associações, contribuindo para a formação de uma memória coletiva, já que se a mesma tag é utilizada para diferentes dados, conectam-se vários documentos da web, ou seja, as tags também fazem parte desse imenso hipertexto que forma a web, o hipertexto 2.o.

No caso do Flickr, assim como em hipertextos construídos coletivamente, através de discussões em comentários de blogs, em páginas wiki, em fóruns de discussão, é possível que qualquer usuário interfira na rede de tags do sistema, e que possa travar discussões a respeito da criação dessas tags. Mas se a idéia das tags é que cada um adicione a tag que melhor lhe convier no momento de recuperar a informação, porque seria necessário discutir sobre a criação dessas tags? Simples, pois essa liberdade toda cria dificuldades na busca pela informação.

De acordo com Xu et. al. (2006, online) "different people can use different terms for the same concept"25, ou como preferem Begelman, Keller, Smadja (2006,online) "people think and tag differently. This creates a noisy tagspace and

\footnotetext{
24 Tradução da autora: 'hipertexto feroz', uma estrutura fora de controle, onde a mesma tag é assinada para diferentes recursos com diferentes sentidos semânticos, e assim associa recursos não relacionados.

25 Tradução da autora: Pessoas diferentes podem usar termos diferentes para o mesmo conceito.
} 
thus makes it harder to find material tagged by other people"26. O tagspace é o problema mais comum que acontece na folksonomia, e ocorre quando as pessoas adicionam a mesma tag para dados diferentes. Xu et. al (2006, online) trazem um exemplo interessante da confusão que pode causar a diferença na atribuição de tags. Os autores ilustram a imagem ${ }^{27}$ abaixo no artigo e perguntam "como você etiquetaria esta imagem?”.

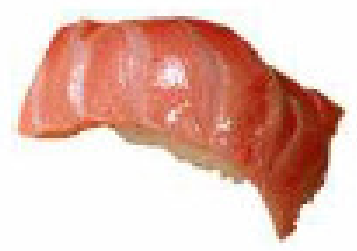

A figura em questão trata-se um de um sushi chamado nigiri. Uma pessoa que não estivesse familiarizada com a denominação específica do sushi poderia adicionar à imagem as tags: food, fish, raw fish, rice Japanese ${ }^{28}$; ao contrário de uma pessoa que conhecendo a especialidade e colocaria tags como: nigiri sushi ou toro. Isso seria um claro caso de tagspace.

Golder e Huberman (apud Marlow, 2006, online) também discutem as dificuldades semânticas do tagging que dificultam a precisão e o andamento da busca num sistema de tags: a) Polissemia: quando uma única palavra tem múltiplos significados relacionados; b) Sinonímia: quando diferentes palavras têm o mesmo significado.

Ainda não foi encontrada uma solução para o problema semântico das tags. Marlow, et. al (2006, online) acreditam que o que poderia auxiliar na resolução do impasse seria a utilização de um sistema de sugestão de tags, onde no momento em que o usuário fosse adicionar a tag fosse disponibilizada uma listagem com as tags mais comuns já relacionadas com aquele dado, o que já se utiliza no del.icio.us.

Em casos como o do Flickr, a sugestão que este trabalho traz é a de discussão entre os usuários dentro do próprio sistema, pois já que existe uma rede de

\footnotetext{
${ }^{26}$ As pessoas pensam e etiquetam diferentemente. Isso cria um espaço de tag ruidoso e assim torna-se mais difícil encontrar material etiquetado por outras pessoas.

${ }_{27}$ Fonte: HYPERLINK "http://www.rawsugar.com/www2006/13.pdf"

http://www.rawsugar.com/www2006/13.pdf

28 Tradução da autora: comida, peixe, peixe cru, arroz japonês.
} 
relacionamentos estabelecida e ferramentas de comunicação como mensagens e comentários, nada mais cabível do que discutir entre os contatos quais tags são melhores para determinadas fotos. Em caráter individual, certamente isto não é necessário, já que o indivíduo vai organizar seus dados da forma como achar melhor, ou seja, vai criar as tags que bem entender. Já no del.icio.us a tarefa é um pouco mais complicada, devido ao fato de que não existe uma rede social, ou seja, os usuários não podem discutir, dentro do sistema, acerca de qual tag será a mais adequada para determinada url. O mais sensato nesse tipo de sistema é seguir as tags já existentes e que aparecem quando o usuário vai etiquetar uma página, bem como sugerem Marlow et. al (2006, online). Caso não existam, aí prevalece o bom senso de cada usuário, o que não deixa de ser também uma construção coletiva, já que a primeira tag certamente será utilizada por outros usuários, que criarão outras com base na primeira.

\section{Considerações finais}

As informações na web estão ganhando uma nova maneira de serem organizadas em função da folksonomia, através das tags, que constituem os links do hipertexto 2.o. Um hipertexto que, além de concretizar objetivos como os de armazenamento de informações em grandes proporções e de forma conectada, como idealizavam Ted Nelson e Bush, traz novas maneiras de organizar os dados na web. As tags reconfiguram o hipertexto até então praticado, contituindo-se como um novo tipo de link, além dos elencados por Landow (2006), contestando Dreyfus (2001), que acredita na existência de um único tipo de link, desprovido de significação e assim se diferenciando dos demais por modificarem a estrutura de organização da Rede, que passa a ser efetuada pelos próprios usuários, de forma coletiva e semântica, ou seja, atendendo aos princípios originários de coletividade do hipertexto e permitindo a busca pelas informações através de significados.

A web 2.0 tem como alguns de seus princípios, elencados por O’Reilly (2005, online) rich user experience ${ }^{29}$, ou seja, quanto mais os indivíduos usam um sistema, mais ele evolui e mais se percebe as necessidades de adaptação; e trust your users ${ }^{30}$ que consiste na importância dada à participação dos usuários da web para seu

\footnotetext{
29 Tradução da autora: Riqueza da experiência do usuário.
}

${ }^{30}$ Tradução da autora: Confie nos seus usuários. 
desenvolvimento. Com a folksonomia, os princípios são absolutamente aplicáveis. Ao disponibilizarem o tagging, o gerenciamento dos dados é delegado ao usuário, que vai, da maneira que lhe for mais conveniente, organizar os arquivos. A experiência do usuário é fonte de riqueza para o avanço da ferramenta. Assim, a prática do tagging é que vai determinar as vantagens e desvantagens desse tipo de atividade, apontando os problemas, como no caso de uma mesma tag para informações diferentes.

A memória coletiva não é intenção, mas conseqüência dessa prática. A folksonomia auxilia na formação de uma rede de associações com base no significado eleito, individualmente, ou por senso comum, mas independente do contexto de criação, com conseqüências colaborativas, no sentido de contribuição para a busca das informações.

A web 2.0, baseada na cooperação, redimensiona-se a cada tag criada, alterando, através da construção coletiva, a rede hipertextual como um todo. A folksonomia e o hipertexto 2.o libertam os usuário da web dos mecanismos estreitos da taxonomia, através da possibilidade de uso de um vocabulário descontrolado, que atende aos formatos originais do hipertexto, permitindo além do armazenamento semântico conectado de informações, o registro, intencional ou não, da memória coletiva na web.

\section{Referências Bilbiográficas:}

BEGELMAN, Grigory; KELLER, Philipp; SMADJA, Frank. Automated Tag Clustering: Improving search and exploration in the tag space. Disponível em: http://www.formatex.org/micte2006/pdf/1364-1368.pdf. 2006.

BURKE, Peter. Uma história social do conhecimento: de Gutenberg a Diderot. Jorge Zahar Editor. Rio de Janeiro, 2003.

BUSH, Vannevar. As We May Think. 1945. Disponível em: http://www.theatlantic.com/unbound/flashbks/computer/bushf.htm.

CASALEGNO, Federico. Memória Cotidiana: Comunidades e comunicação da era das redes. Editora Sulina. Porto Alegre, 2006.

CHARTIER, Roger. Os desafios da escrita. São Paulo: Unesp, 2002.

DREYFUS, Hubert L. On the Internet. Londres: Routledge, 2001. 
HALBWACHS, Maurice. A Memória Coletiva. Centauro Editora. São Paulo 2004.

LANDOW, George. Hypertext 3.0: Critical Theory and New Media in an Era of Globalization. The Johns Hopkins University Press. Baltimore, 2006.

LÉVY, Pierre. As Tecnologías da Inteligência. Editora. 34. São Paulo, 1993.

MARLOW, Cameron; NAAMAN, Mor; BOYD, Danah; DAVIS, Marc. Position Paper, Tagging, Taxonomy, Flickr, Article, ToRead. 2006. Disponível em: http://www.rawsugar.com/www2006/29.pdf 2006.

MARTINS, Beatriz Cintra. Cooperação e livre fluxo da informação: A influência da cultura hacker na definição dos padrões da Comunicação Mediada por Computador. 2006. Disponível em:

http://www.unirevista.unisinos.br/index.php?e=3\&s=30\&a $=615$

O'REILLY, Tim. What is Web 2.0?. 2005. Disponível em: http://www.oreillynet.com/pub/a/oreilly/tim/news/2005/o9/30/what-isweb-20.html. 2005.

PRIMO, Alex. O Aspecto Relacional das Interações na Web 2.o. In: XXIX INTERCOM: Congresso Brasileiro de Ciências da Comunicação, 2006, Brasília, Anais... Brasília, 2006.

PRIMO, Alex; RECUERO, Raquel. A Terceira Geração da Hipertextualidade. Revista da Faculdade de Comunicação Casper Líbero, p. 83;93. São Paulo, 2006.

SEPUlVEDA, Myrian dos Santos. Memória Coletiva Teoria Social. Annablume. São Paulo, 2003.

XU, Zhichen; FU, Yun; MAO, Jianchang; SU, Difu. Towards the Semantic Web: Collaborative Tag Suggestions. Disponível em:

http://www.rawsugar.com/www2006/13.pdf. 2006. 